\title{
KATARSIS \\ LISBON WORKSHOP 2008
}

AnA Estevens ${ }^{1}$

ANDRÉ CARMO ${ }^{2}$

Entre 28 de Janeiro e 1 de Fevereiro de 2008, decorreu na Faculdade de Letras da Universidade de Lisboa o 5. ${ }^{\circ}$ Workshop da Acção de Coordenação KATARSIS, organizado por Isabel André e pela equipa do Centro de Estudos Geográficos. Pretendeu-se com este workshop promover o debate entre os investigadores do KATARSIS e os stakeholders convidados e trazer para discussão três questões: criatividade bottom-up; governância multi-escalar ${ }^{3}$ e inovação social.

Este projecto, desenvolvido no âmbito do $6{ }^{\circ}$ Programa-Quadro de Financiamento da Comissão Europeia, sob coordenação de Frank Moulaert do Global Urban Research Unit (GURU) da Universidade de Newcastle, funciona como uma plataforma que reúne equipas de 18 centros de investigação, cujo principal interesse se prende com o estudo da promoção e mobilização, individual ou colectiva, de estratégias baseadas na criatividade e na inovação social, que contribuam para a resolução de problemas de desigualdade ou exclusão social. É estimulada a colaboração entre as diversas equipas, através da troca de experiências e conhecimentos, com vista a uma melhor integração dos seus projectos e metodologias de investigação ${ }^{4}$. Para a geografia, este projecto é particularmente relevante pois a dimensão espacial, nomeadamente a escala local, é considerada fundamental, não só para a contextualização das estratégias inovadoras, como para a valorização da diversidade, e para gerar a interacção a geração entre os actores e criar espaços alternativos que permitam a superação da alienação a que estão sujeitos os indivíduos ou as comunidades.

O workshop decorreu durante cinco dias, quatro dos quais dedicados à apresentação de comunicações e sua discussão e um preenchido com uma visita de estudo a Montemor-o-Novo. Na sessão de boas-vindas participaram Teresa Barata Salgueiro, na qualidade de Presidente da Comissão Executiva do Departamento de Geografia, e Isabel André, enquanto representante da instituição de acolhimento (CEG-UL), a que se seguiu

1 Doutoranda de Geografia Humana na FLUL. E-mail: anaestevens@gmail.com

2 Doutorando de Geografia Humana na FLUL. E-mail: andrecarmo83@gmail.com

3 No contexto desta notícia, é utilizado o termo "governância multi-escalar" - em vez de "governância multi-level" como na formulação original do projecto. Isto prende-se com o facto de esta questão ter sido discutida no âmbito do workshop e se ter chegado à conclusão de que o conceito de governância multi-escalar seria mais apropriado. O conceito de governância multi-level foi considerado um conceito estático (dos níveis local, nacional, regional, etc.), enquanto o conceito de governância multi-escalar traduz uma visão mais dinâmica, negociada e móvel.

4 Para mais informações ver http://katarsis.ncl.ac.uk/project.html 
uma breve apresentação do projecto KATARSIS, a cargo de Frank Moulaert. Após esta primeira sessão plenária, decorreram quatro sessões paralelas que incidiram sobre os seguintes domínios:

- WP 1.1. Mercado de trabalho, emprego e economia social (coordenação de Isabel André, Universidade de Lisboa): foram apresentados quatro casos práticos (Associazione Olinda - Milão; Associação João Cidade - Montemor-o-Novo; Association des Foyers Internationaux - Paris; Lawaetz Foundation - Hamburgo) e discutidas questões como as relações entre a escala local das iniciativas da economia social e o carácter global das visões que as inspiram, bem como a emergência de novas redes de cooperação e de solidariedade e a necessidade de dar visibilidade a novos contextos.

- WP 1.2. Educação e Ensino (coordenação de Bas Tierolf, Instituto Verwey-Jonker, Utrecht): a discussão centrou-se em três pontos - i) práticas bottom-up vs topdown; ii) enquadramento político-institucional e estratégias socialmente criativas; iii) combate às desigualdades através de estratégias socialmente criativas.

- WP 1.3. Habitação e infra-estruturas de vizinhança (coordenação de Stuart Cameron, Universidade de Newcastle upon Tyne): a discussão decorreu em torno do artigo "Changing Patterns of Social and Ethnic Residential Segregation in Budapest". Destaca-se a conceptualização apresentada por Stuart Cameron, que distingue entre exclusão do acesso à habitação e exclusão através da habitação, defendendo a importância dos lugares (place matters) enquanto fontes de práticas organizacionais e, também, o reconhecimento destes enquanto espaços que podem contribuir para a exclusão social.

- WP 1.4. Saúde e Ambiente (coordenação de Judy Orme, Universidade de Western England, Bristol): foram apresentados diversos projectos caracterizados pela adopção de estratégias socialmente criativas ("Social Innovation in Mental Health: Public Places as Instruments for Recognition", "The Green House of Køge"; "A new life, a new project: early pregnancy in social disadvantaged situations" e "Farming Practices and Chemically Safer Food/ Cancer Disease Prevention") e discutidas as relações entre bem-estar, comunidade e estratégias socialmente criativas.

O primeiro dia terminou com uma sessão plenária, em que foram apresentados alguns dos resultados e conclusões resultantes das sessões paralelas. Entre outros aspectos, foi feita referência à necessidade de os actores deterem o poder de decisão, controlando a forma como os processos se desenrolam; à importância assumida por questões como a reflexividade, a contextualização e a adopção de uma perspectiva de longo prazo para o sucesso das práticas inovadoras; à relevância dos novos tipos de relações e o modo como estas se articulam a diferentes escalas; ao papel das estruturas de poder no domínio da habitação, ou seja, do papel desempenhado pelo Estado e pela Comunidade.

No segundo dia do workshop, a discussão centrou-se na necessidade de reconceptualizar algumas noções fundamentais, tais como as de cultura, arte e 'bottom-up strategies', devido ao crescente economicismo, intrínseco ao contexto neoliberal contemporâneo e à necessidade de se desenvolverem um conjunto de conceitos e de teorias que articulem reflexão teórica e actividade prática. A par desta questão, foram também discutidas a necessidade de reflectir sobre a existência, ou não, de relações entre a cultura e a economia; o pensamento sobre as relações de poder, ou seja, determinar 'what 
is bottom... and what is up'; a ideia de que apenas uma definição lata de arte pode ter um carácter emancipador ${ }^{5}$.

No terceiro dia, decorreu a visita a Montemor-o-Novo (fig. 1). Esta pequena cidade alentejana é um exemplo muito interessante de boas práticas em termos de estratégias e dinâmicas sociais, culturais e artísticas. A visita começou com uma breve passagem pela biblioteca municipal, onde o presidente da Associação João Cidade e Maria do Resgate Almadanim fizeram a apresentação desta associação. A Casa João Cidade é uma Instituição Particular de Solidariedade Social que inclui entre os seus objectivos o desenvolvimento de uma comunidade sócio-terapêutica, destinada a jovens e adultos com deficiência mental, trabalhando através das artes. Após uma breve apresentação do projecto, seguiu-se uma visita às oficinas ou ateliers da Casa João Cidade. A parte da tarde foi preenchida com uma visita a "O Espaço do Tempo" - uma estrutura transdisciplinar, situada no Convento da Saudação e dirigida por Rui Horta (coreógrafo e bailarino), que serve de apoio a inúmeros criadores nacionais e internacionais. Os promotores deste projecto consideram que "a cultura pode ser um factor importante de desenvolvimento local, abrindo novas perspectivas aos habitantes, ajudando a qualificar o seu desempenho profissional, possibilitando inúmeras formas de abertura ao mundo e gerando emprego e investimento local"6. "O Espaço do Tempo" colabora com as escolas, associações e instituições do concelho através da realização de workshops, acções de formação com professores e alunos na área das marionetas, trabalho coreográfico com os alunos da EB 2.3, e uma acção de formação ao longo do ano dedicada especificamente a professores, agentes culturais e criadores. Paralelamente, acolhem criadores internacionais, algo que consideram fundamental no cruzamento com os criadores portugueses, desenvolvendo também trabalho em redes internacionais e portuguesas. Para "O Espaço do Tempo", Montemor-o-Novo funciona

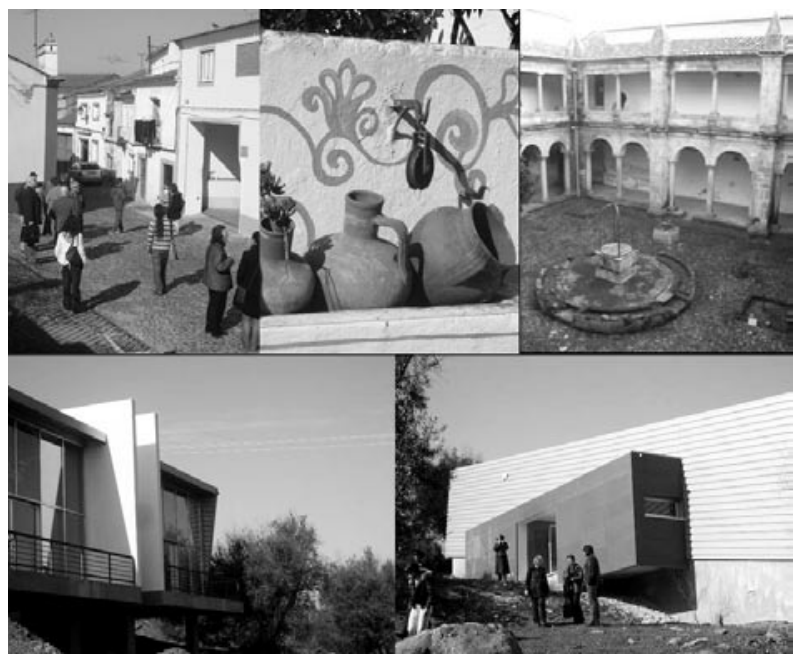

Fig. 1 - Visita a Montemor-o-Novo, Janeiro 2008

Fig. 1 - Visit to Montemor-o-Novo, January 2008

5 Para mais informações ver http://katarsis2wp.wordpress.com/

6 Fonte; http://www.oespacodotempo.pt 
para os artistas como "um 'porto de abrigo', um antigo espaço de clausura religiosa (dominicana) e agora um espaço de 'clausura' criativa."7

No quarto dia, a discussão girou em torno de questões relacionadas com a governância, tendo por base novas tendências e processos de governância (multi-escalar) e a forma como se articulam com a democracia e a sociedade civil. Do debate que se seguiu, resultaram as seguintes conclusões: a) verifica-se uma crescente desresponsabilização do Estado-providência ao nível da provisão de algumas das necessidades mais básicas que passam a ser da responsabilidade do terceiro sector; b) as estratégias actuais vão no sentido de aumentar a auto-exploração, diminuindo os custos da reprodução social; c) as estratégias bottom-up tornam-se frágeis devido às incertezas no seu financiamento. Para complementar a discussão teórica da manhã, foram apresentados alguns exemplos de estratégias socialmente criativas: i) Institut Català del Sòl (INCASOL), uma organização com base em Barcelona que procura responder aos problemas urbanos causados pelas modificações sociodemográficas decorrentes das migrações ocorridas nos anos 90 e primeira década do século XXI; ii) Mehr Demokratie, uma organização que procura fomentar o desenvolvimento de formas alternativas de voto, ou seja, fomentar a reestruturação do sistema democrático através de formas de participacão assentes na democracia directa; iii) Lokale Agenda 21 Wien, que medeia a cooperação entre políticos, administração pública e grupos de cidadãos auto-organizados, com vista à definição e prossecução de projectos que visem o desenvolvimento sustentável; iv) Association des Foyers Internationaux (AFIP), uma organização não governamental cujos membros se opõem à discriminação das minorias étnicas, procurando promover a sua inserção no mercado de trabalho; e v) L'Ateneu 9, uma organização de Barcelona que concebe a arte como instrumento de transformação, alicerçando-se nos valores da criatividade e da inovação.

Finalmente, o último dia do workshop foi dedicado ao debate da inovação social e, em particular, à reconceptualização de alguns conceitos fundamentais (política, economia e sociedade), no âmbito dos resultados da primeira fase do KATARSIS. Isto é também importante para a compreensão epistemológica das diferentes abordagens usadas para compreender a inovação social e para o reconhecimento da existência de múltiplos percursos para a atingir. Em seguida foram apresentadas visões da inovação social relativas a cinco áreas do conhecimento: i) geografia; ii) economia política; iii) cultura e arte; iv) educação; v) sustentabilidade ambiental. Foram aqui discutidas questões como a importância da escala local para uma melhor governância, a necessidade de uma economia social baseada nas relações existentes dentro das comunidades, a circulação de informação pela cidade através de diferentes formas, a necessidade de ultrapassar a rigidez e a conformidade que caracterizam os sistemas educativos tradicionais e a importância dada às questões da sustentabilidade ambiental.

Após cinco dias de workshop do projecto KATARSIS, é possível salientar as seguintes ideias: i) a importância de valorizar a relação entre a teoria e a prática; nesse sentido, assinala-se o esforço meritório por parte dos participantes em fazer convergir os discursos académico e do "terreno"; ii) a necessidade de envolver todos os intervenientes, mantendo sempre uma postura crítica face ao papel dos lugares (ou seja, evitando o erro da sua romantização, como muitas vezes acontece quando se trata de pequenas comunidades); iii) a importância de reconhecer que, apesar das inúmeras potencialidades associadas a projectos desta natureza, existem diversos constrangimentos, tais como contextos políticos desfavoráveis, conjunturas económicas recessivas e realidades sociais em convulsão, que tornam mais difícil o seu sucesso; iv) a importância de explorar e reconceptualizar alguns conceitos fundamentais para a compreensão das diferentes abordagens usadas na inovação social.

7 Fonte; http://www.oespacodotempo.pt 